\title{
A CLÍNICA PSICANALÍTICA DAS PSICOSES EM INSTITUIÇÕES DE SAÚDE MENTAL
}

\author{
Cleide Pereira Monteiro* \\ Edilene Freire de Queiroz ${ }^{* *}$
}

\section{RESUMO}

Nosso propósito é refletir sobre a clínica psicanalítica das psicoses em instituições de saúde mental, tema que de um lado suscita questões e impasses para o método clínico psicanalítico e, de outro, contribui para renovar o lugar da descoberta freudiana. Abordaremos, primeiramente, a clínica das psicoses para, em seguida, refletir sobre a prática psicanalítica em instituições de saúde mental. Neste último segmento, daremos destaque aos depoimentos de psicanalistas atuantes em tais instituições; eles apontam para uma prática feita por muitos cujo foco incide numa clínica do sujeito. $\mathrm{O}$ modo de produção subjetiva se dá pela via da "trivialização", uma manobra preciosa usada pelos analistas e demais técnicos que compõem a equipe institucional para neutralizar a ação do delírio. Tal manobra exige do analista uma certa dose de invenção, espírito de humor e um certo desprendimento do desejo de interpretar.

Palavras-chave: clínica, psicoses, prática psicanalítica, sujeito, trivialização

\section{AbSTRACT}

THE PSYCHOANALYTIC CLINIC OF THE PSYCHOSIS IN MENTAL HEALTH INSTITUTIONS

It is our purpose to ponder over the psychoanalytic clinic of psychoses in mental health institutions, a theme that, on the one hand, raises questions and dilemmas to the psychoanalytic

* Psicanalista, Mestre em Psicologia Clínica pela UNICAP, Membro aderente da Escola Brasileira de Psicanálise, Coordenadora da Delegação Paraíba da Escola Brasileira de Psicanálise, Tutora do Io Curso de Especialização em Saúde Mental da UFPB.

** Psicanalista, Doutora em Psicologia Clínica pela PUC-SP, Pós-doutorado no Laboratoire de Psychopathologie Clinique - Marseille 1, Professora titular, Coordenadora do Programa de Mestrado em Psicologia Clínica e Membro do Laboratório de Psicopatologia Fundamental e Psicanálise da UNICAP, Membro da Associação Universitária de Pesquisa em Psicopatologia Fundamental. 
clinic method, and on the other, contributes to renew the Freudian discovery. Firstly, we will approach the psychoses' clinic, and after that, we will discuss the social and clinical extension of psychoanalysis; then, we shall focus on the psychoanalytical practice in mental health institutions. In this last segment, we will point out the testimony of psychoanalysts who act in such institutions; they point out to a practice by many whose focus is on a subject clinic. The mode of subjective production occurs through "trivialization", a precious maneuver used by analysts and other technicians who make up the institutional team, in order to neutralize the delirium action. Such procedure requires from the analyst a certain degree of invention, humor and detachment of the wish to interpret.

Keywords: clinic, psychosis, psychoanalytic practice, subject, trivialization

"A liberdade que Freud se deu aí foi simplesmente aquela, decisiva em tal matéria, de introduzir o sujeito como tal, o que significa não avaliar o louco em termos de déficit e de dissociação das funções".

(Lacan, 2003: 220)

\section{INTRODUÇÃO}

Debruçamos-nos, ao longo da pesquisa $A$ clínica das psicoses e a prática psicanalítica nas instituiçôes públicas de saúde mental, em torno de dois eixos temáticos caros à psicanálise: psicose e prática institucional. Ambas trazem questôes e impasses, os quais não pertencem à ordem de uma impossibilidade; ao contrário, contribuem para renovar o lugar da descoberta freudiana em sua secular existência no mundo.

Tentamos fazer da pedra que sempre existirá no meio do caminho, como nos lembra o poeta Carlos Drummond no poema No meio do caminho, não uma impossibilidade, mas antes um bom motivo para prosseguirmos em nossa aventura. A exemplo do herói da mitologia grega, Sísifo, que com sua pedra localizase ora no sopé da montanha, ora em seu cimo, sem se fixar em nenhuma dessas posiçôes, concluímos a pesquisa com o entusiasmo de saber que o movimento da pedra que rola produzirá novos contornos e outros re-posicionamentos.

No decorrer de nossa investigação, abordamos, em um primeiro momento, o tema da clínica das psicoses na perspectiva da psicanálise, a partir do que nos foi possível avançar, em um segundo momento, nas questôes concernentes a sua inserção nas instituições públicas de saúde mental. A pesquisa a partir dos referidos 
eixos constitui um desafio. Primeiro porque a psicanálise é considerada uma prática clínica exercida no âmbito do privado, tendo no chamado consultório particular o locus específico de sua práxis; e segundo porque a descoberta freudiana deu-se no âmbito da histeria, portanto, no campo das neuroses e não no das psicoses. Hoje é possível conceber a aplicação da psicanálise a outros quadros psicopatológicos que extrapolam as peculiaridades de uma clínica voltada a neuróticos. Entretanto, permanece o questionamento sobre como efetivamente requerer o seu uso em espaços públicos. Investigamos, então, a experiência de uma extensão clínica e social da psicanálise, considerando as indicações de Sigmund Freud e os ensinamentos de Jacques Lacan.

Para isso, foi preciso sair de uma visão mais ortodoxa que não considera o método clínico psicanalítico passível de aplicação em outros contextos, fora do enquadre tradicional. Analisamos o uso do dispositivo analítico em sua forma ampliada ao campo que se convencionou chamar de "saúde mental". Sabemos que a inserção da psicanálise nesse contexto é complexa e algumas vezes polêmica, visto que aquele é um campo heterogêneo, revestido de certas peculiaridades que extrapolam as questôes pertinentes ao específico da psicanálise. No entanto, quando o analista não recua frente às dificuldades, depara-se com o desafio de localizar o seu lugar na instituição sem perder de vista o específico de sua posição. Para isso, é preciso destituir o status de especialista e passar à posição de "analista-cidadão", "um a mais" em uma prática feita por muitos. No dizer de Laurent:

Os analistas têm que passar da posição de analista como especialista da desidentificação à de analista cidadão. Um analista cidadão no sentido que tem esse termo na teoria moderna da democracia. Os analistas precisam entender que há uma comunidade de interesses entre o discurso analítico e a democracia, mas entendê-lo de verdade! Há que se passar do analista fechado em sua reserva, crítico, a um analista que participa; um analista sensível às formas de segregação; um analista capaz de entender qual foi sua função e qual lhe corresponde agora (Laurent, 1999: 13).

Assim, a posição contemporânea do analista é mais a de ser um "analistacidadão", sintonizado com os modos de subjetividade de seu tempo. Em uma civilização da proliferação do discurso científico, o sintoma já não é mais o mesmo que fascinou Freud por ser decifrável. Vivemos a época do sintoma mudo, paralisado pelos curtos-circuitos do gozo. Freud (1928) nos ensina que o malestar inerente à cultura provém da defasagem que há entre o que se busca e o que se encontra, entre o universal e o que não pode ser coletivizável. O produto desse 
encontro faltoso é a emergência do desejo. Hoje, a ciência oferece objetos que tamponam a falta estrutural e estruturante, coletivizando o modo de satisfação com a política do "todos iguais".

As políticas públicas de saúde mental também sofrem ressonâncias de um movimento que acontece em todas as esferas sociais. Não obstante, o objeto com o qual o analista trabalha não se reduz à dimensão do universal. $\mathrm{O}$ analista de hoje vive em uma época fragmentada entre a globalização e as exigências de singularidade. Como método de tratamento e de investigação, a psicanálise se insere em uma ética fundada a partir da solução singular dada pelo sujeito à errância do seu desejo e a seu modo de gozo.

Seguindo essa orientação, nossa preocupação foi a de demonstrar como a prática psicanalítica pode ser ampliada sem subverter os fundamentos que dão sustentação a sua especificidade, pois, mesmo quando o método de tratamento inventado por Freud é aplicado a outros contextos, deve conservar o que o define como psicanalítico. Insistimos que o analista, quando orientado por princípios que regem a psicanálise, pode e deve sentir-se convocado a intervir em outros espaços de atuação. Isso não o faz desviar-se da ética que sustenta seu campo de ação analítica.

Recorremos à contribuição que Lacan (1998a) nos oferece ao postular o conceito de psicanálise em extensão, o qual se prestou muito bem para o avanço na aplicabilidade dos fundamentos da psicanálise a outros campos do saber. Situando nossa pesquisa na psicanálise aplicada à terapêutica, um dos segmentos da psicanálise em extensão, lançamos-nos ao desafio de investigar o que caracteriza ou determina uma prática psicanalítica nas instituições públicas de saúde mental que se destinam ao tratamento de pacientes psicóticos. Com o propósito de atingir este objeto geral da pesquisa, fizemos uma investigação na literatura sobre a problemática bem como fomos a campo e interrogamos psicanalistas e/ou profissionais que se pautam pelo referencial psicanalítico, vinculados aos serviços públicos de assistência à psicose, situados na cidade do Recife-PE.

Entrevistamos seis profissionais, entre os quais quatro trabalham nos Centros de Atenção Psicossociais (CAPS); os outros dois, em hospital psiquiátrico. Convidamos os referidos profissionais a falarem sobre sua prática, quer seja no hospital psiquiátrico ou nos serviços substitutivos a este. $\mathrm{O}$ recurso das entrevistas nos auxiliou a estabelecer as particularidades que perpassam a ação analítica no âmbito da instituição de saúde mental. Foi possível através delas fundamentar a proposta de se exercer a psicanálise na instituição, abordando a questão do que pode fazer o analista no contexto institucional a partir do específico de sua posição. Como observa Ana Cristina Figueiredo, "O psicanalista não é especial. É 
específico. Só assim ele convém” (Figueiredo, 1997: 168). Percebemos que o trabalho dos analistas nas instituiçôes tem que ser inventado, cotidianamente, devido às inúmeras variáveis que atravessam a sua prática. Mas como têm operado efetivamente aqueles que se guiam pela psicanálise em seu trabalho institucional?

A partir do material colhido na pesquisa, elegemos três frentes de ação do trabalho do analista na instituição: 1) A atuação frente ao específico do caso, visando o advento do sujeito. Nesse sentido, destacamos a construção do caso clínico como um instrumento da prática, e a escuta clínica a partir do delírio; 2) A participação do analista na equipe, destacando algumas contribuições da escuta psicanalítica em uma prática feita por muitos; 3) Por fim, a incidência da escuta psicanalítica na atuação junto à família. Tais recortes nos possibilitaram conceber uma "função multiuso" do analista, sobretudo nos novos serviços de assistência.

\section{UMA PRÁTICA FEITA POR MUITOS ${ }^{2}$}

O analista que não recua frente ao trabalho analítico na instituição está disponível para o uso que se fizer dele. Suas múltiplas facetas não invalidam o específico de sua posição: o analista como aquele que possibilita localizar e trazer para a cena o que dela está excluído e, desse modo, fazer circular a causa do desejo para que ali haja sujeito, possibilitando o tratamento do gozo, o qual está desmedido na psicose.

A experiência institucional com psicóticos possibilita ao analista confrontarse com uma atuação que requer uma abordagem diferenciada daquela habitualmente adotada no âmbito do consultório privado. No entanto, defendemos a perspectiva de que é possível, sim, estabelecer uma "clínica do sujeito" quando nos referimos ao tratamento psicanalítico aplicado às psicoses. Aliás, "introduzir o sujeito como tal” (Lacan, 2003a: 220) é o ponto de partida da posição ética que o analista deve assumir na política institucional. Ali onde está o indivíduo com sua história, com seu delírio, o sujeito de direito deve advir, o que o torna responsável pela sua condição de existência.

Nessa perspectiva, na proposta de reabilitação psicossocial, introduzimos a de inclusão subjetiva, na qual é preciso fazer comparecer a dimensão da clínica em uma "prática feita por muitos". Partimos do pressuposto de que excluir a clínica não é só deixar de fora a psicanálise do campo da saúde mental, é também promover a própria exclusão do sujeito. Assim, assegurar a dimensão da clínica na prática institucional é sustentar o lugar social do sujeito a partir de sua diferença, e não do universal dos direitos de cidadão. Isso pode ser feito através da posição de escuta do analista sobre o que há de específico em cada sujeito. Nos serviços 
substitutivos ao hospital psiquiátrico, é através do TR (técnico de referência) que o tratamento é singularizado. Observamos que a função de escuta do TR pode ser considerada uma herança da clínica que ocorre no contexto institucional. Como TR, o técnico não pode prescindir de uma escuta particularizada do caso.

Assim, corroborando a idéia de que o principal eixo de contribuição da psicanálise no campo da saúde mental é a questão do sujeito, nos lançamos no desafio de propor algumas vias de acesso à produção subjetiva. Mesmo não tendo formalizado uma teoria do sujeito - foi Lacan que o fez -, a proposta de escutar os conflitos subjetivos dos pacientes faz de Freud o fundador de uma clínica do sujeito. É possível renunciar à proposta freudiana quando nos referimos ao tratamento das psicoses? Não só no âmbito da teoria, mas também no da prática psicanalítica na instituição, admitimos ser importante interrogar sobre o advento do sujeito na psicose. Considerar as vias de acesso à produção subjetiva é fundamental na medida em que na psicose o sujeito não comparece nas tradicionais formações do inconsciente (sonhos, atos falhos, sintomas etc). Como diz Lacan, "o psicótico é um mártir do inconsciente, dando ao termo mártir seu sentido, que é o de testemunhar" (Lacan, 1988a: 153).

Nesta perspectiva, elegemos três vias de acesso à produção de um sujeito na psicose: o trabalho com o delírio, a via da trivialização e o trabalho com a arte, todas perpassadas pelas transferências múltiplas próprias ao contexto institucional.

As conseqüências que advêm das formulações de Lacan, ao longo de seu ensinamento, sobre a questão do sujeito na psicose permitem-nos dizer que a operação subjetiva pode ser realizada na medida em que é possível considerar a via do delírio. É bem esse o ensinamento que encontramos de forma magistral nas Notas de Freud dedicadas ao Presidente Schreber. Freud "escuta" nas Memórias um testemunho extraordinariamente rigoroso do que vem a ser o trabalho do delírio, a partir do qual se produz um sujeito.

$\mathrm{O}$ trabalho com o delírio deve estar baseado em outros princípios que não sejam os da psiquiatria. O delírio tem sido a via princeps do acesso da Psicanálise ao mundo das psicoses; seu bom uso pode promover o advento de um sujeito, destituindo-o da condição de objeto de gozo do Outro, posição na qual o psicótico se encontra. Uma das advertências do psicanalista na rede é a de que o delírio é um modo de expressão subjetiva, não devendo ser debelado a todo custo, mas usado na perspectiva da construção de uma metáfora delirante, através da qual significante e significado se estabilizam, possibilitando um efeito de significação. A trajetória de Schreber, por exemplo, vai da posição de objeto entregue aos caprichos do Outro (seu médico Flechsig e o próprio Deus) à eleição da metáfora delirante: "ser a mulher de Deus". 


\section{A VIA DA TRIVIALIZAÇÃo}

Elegemos um outro modo de produção subjetiva, a via da "trivialização", que vai na contramão do delírio, quando este é uma ameaça que pode provocar atuações ou até mesmo passagem ao ato. Observa Miller (citado por Ferreira e Trópia, 2000) que, em se tratando da demanda psicótica, uma manobra preciosa a ser usada pelo analista e demais técnicos seria aquela de "buscar a maior trivialidade possível que levaria a uma possibilidade de uma vida comunitária mínima, uma vida comum" (Ferreira, 2000: 146). Tal estratégia pode servir para esvaziar a força que tem o delírio de capturar o sujeito em sua condição de objeto. Neste sentido, ao invés de privilegiar temas que incitem o delírio, é importante dar destaque àqueles que sejam corriqueiros, uma conversa ordinária sobre aspectos do dia-a-dia.

O exemplo clínico a seguir, de um dos entrevistados da pesquisa, serve-nos para ilustrar uma ação do analista que visa barrar o delírio pela via da trivialização. Ao analista foi possível encontrar uma "solução" de manobra transferencial a partir de uma "simples intervenção":

Hoje mesmo eu estava com um usuário que disse:

- "Eu vou embora, eu vou embora porque aqui, esse barulho, os carros estão querendo me buscar, me pegar”.

Ele sempre está me procurando para falar comigo, a solução que eu vi foi:

- Por que você vai me deixar, com quem eu vou conversar hoje?

E ele:

- "Ah, você quer conversar comigo?".

- Mas é claro que eu quero.

Ele se tranqüilizou com essa simples intervenção. Aí ele começou a falar comigo, de como ele estava com alguns problemas em casa, com a família, com o irmão que estava sendo grosseiro com ele. E aí a gente pôde ter um diálogo e isso deu a ele a tranqüilidade que ele precisava para permanecer. O diferencial do manicômio é exatamente esse: quando vem uma situação dessa, se medica, se faz a contenção física, e aqui nós fazemos a contenção que eu chamo de afetiva. Você contém pelo vínculo que você tem com esse usuário.

Qual o valor de uma "simples intervenção" em momentos chaves da demanda psicótica? A manobra feita pelo profissional, que utiliza o vínculo, a "contenção afetiva”, como ele o chama, teve como efeito barrar a terrível invasão de gozo que o levava a querer sair correndo pelas ruas, pois tinha um Outro que o invadia, 
representado pelos carros que faziam barulho e que queriam pegá-lo. Sem apelar para a interpretação, a intervenção simples, trivial - "por que você vai me deixar..." - faz com que o delírio perca sua força, sofra um esvaziamento de sentido e, conseqüentemente, de gozo.

A transferência, desse modo, pode ser manobrada a partir dos sinais dados pelo paciente. Obviamente, exige do analista uma certa dose de invenção para operar, e até mesmo de espírito de humor, desprendendo-se, assim, do furor interpretativo de dar sentido. Nessa perspectiva, Eric Laurent, durante $A$ conversação de Arcachon (Miller et al., 1998: 125), retomando os ensinamentos de Lacan a partir da "segunda clínica”, observa: "Toda a teoria da transferência está em jogo na segunda clínica: é preciso fazer-se de capitonê e do destinatário desses sinais mínimos. É preciso entrar na matriz do discurso pelo sinal e não pelo sentido, o que supõe decidir que existe aí uma entrada possível”.

É preciso, consoante Laurent na Conversação (Miller et al., 1998: 125), uma disponibilidade do analista e uma vontade férrea de sua parte, para se fazer destinatário do paciente. Essa tenacidade renova a função de "secretário do alienado" (Lacan, 1998a: 235). Tal função designa a posição do analista diante da demanda psicótica, "pode-se entendê-la no sentido copista, ou então no sentido de Hegel quando ele diz: 'o filósofo é o secretário de história'. O secretário é quem tem o conceito, ele escolhe ser o destinatário da história, ouvir com atenção isso, mais do que aquilo", conclui Laurent na Conversação (Miller et al., 1998: 125). O segundo sentido amplia a função do analista enquanto um secretário ativo, que dá mais atenção a alguns aspectos em detrimento de outros. No campo da saúde mental, são muitos aqueles que dividem com o analista o lugar de destinatário, possibilitando, assim, que a transferência seja mantida na trivialidade.

Ainda nessa direção de produção subjetiva, a prática analítica institucional tem se interessado por outras modalidades de intervençôes, como a criação artística dos usuários. Com Lacan (2003b), em seu texto Joyce, o Sintoma, sabemos da psicose não desencadeada de James Joyce, que teve na escrita seu ponto de ancoragem. Poderíamos lembrar de tantos outros, João, José, Maria, Arthur Bispo, que encontram na produção artística um meio de reatar a pulsão desarticulada à cadeia significante. Mas, para que a criação possa funcionar como arranjo sintomático, percebemos que é preciso que um Outro (o analista ou outro técnico) seja destinatário dessas produções.

No entanto, tais produções, mesmo as que são reconhecidas como obra de arte, têm um propósito diferente da criação no campo da neurose. O sujeito neurótico cria a partir da falta instaurada pela castração. Sua via é a da sublimação, tida por Freud como um dos destinos da pulsão sexual. A criação do psicótico, ao 
contrário, dá-se sobre o fundo da ausência da metáfora paterna, tendo, desse modo, um propósito diferente do ato sublimatório do neurótico. Ela é considerada um arranjo sintomático, realizado pelo sujeito sem a recorrência à suplência neurótica do Nome-do-Pai, tendo por função dar um tratamento ao gozo que o invade e aniquila, na psicose.

Em nossa pesquisa de campo, observamos que as atividades desenvolvidas nas oficinas de arte das instituições de saúde mental podem funcionar como catalisadores do ato criacionista. Nas instituições pesquisadas, essa atividade é responsabilidade do terapeuta ocupacional; pensamos, porém, que a psicanálise muito pode contribuir com esse trabalho, na medida em que tenta estabelecer uma articulação do trabalho criativo com a emergência de produção subjetiva. Nesta perspectiva, defendemos que as oficinas não devem funcionar apenas com a intervenção de um terapeuta ocupacional; devem contar também com a de um psicanalista, que ficará atento à expressão subjetiva de cada paciente, que se dá a partir do seu fazer singular. $O$ trabalho criativo é um recurso que deve ter relação mais direta e efetiva com o tratamento do sujeito.

$\mathrm{O}$ ato criacionista no sentido mais amplo, incluindo certos recursos cada vez mais utilizados, como o desenho, o barro, a pintura, o salão de beleza, a arte culinária, entre outros, são, para a psicanálise, expedientes que podem ser aplicados na promoção de laços sociais, além de agir como possibilidade de extração do objeto, servindo de borda para o gozo invasor do Outro, provocando no sujeito um efeito apaziguador.

\section{CONSIDERAÇÕES FINAIS}

Como podemos observar, o panorama é desafiador, várias são as possibilidades de contribuição da psicanálise ao trabalho institucional com pacientes psicóticos. Qualquer que seja o recurso utilizado na instituição, quando a prática psicanalítica faz parte desse contexto o trabalho estará sempre atrelado à escuta singular do caso, pois, para que uma rede de sustentação subjetiva, e conseqüentemente social, possa, de fato, ser efetivada é necessário que o trabalho coletivo realizado no contexto institucional não prescinda do individual, e vice-versa.

$\mathrm{Na}$ junção do trabalho feito a partir da singularidade (psicanálise) e de uma ação coletiva (campo da atenção psicossocial), destacamos a construção do caso clínico como um instrumento privilegiado que possibilita o diálogo da psicanálise com os demais saberes que fazem parte dos novos dispositivos de assistência à saúde mental. Introduzir tal operador na lógica implementada pela Reforma Psiquiátrica exige do 
analista a aposta de que "há uma brecha em algum lugar, e é preciso entrar", como sugere Miller (2002-2003) $)^{3}$ em "Um esforço de poesia" (lição de 29/01/2003). Frente aos chamados programas de reinserção, que trabalham com os aspectos mais pragmáticos do cotidiano do usuário, é preciso que encontremos a brecha por onde podemos nos fazer presentes como uma garantia do particular.

Nesse sentido, na construção do caso, a decisão sobre que encaminhamento dar, em cada caso, se impõe a partir do momento clínico, do saber que é extraído do paciente. Assim, indo além das especialidades, é o Um do caso que nos permite adotar, no campo da saúde mental, uma "prática feita por muitos" (Laurent, 2000: 168). O projeto terapêutico individual (PTI) é orientado pelas indicações dadas pelo sujeito.

Nessa perspectiva, é preciso que haja o destaque na vida de um sujeito, ou até mesmo a invenção de uma "fórmula sintomática" que possa funcionar como suplência à hiância central do simbólico. "A clínica das suplências", como a denominamos em nossa investigação a partir do último período do ensino de Lacan, tem por propósito fazer funcionar a amarração dos três registros (real, simbólico e imaginário) que organizam o mundo subjetivo. Assim, é importante que o tratamento permita ao sujeito reinventar representações simbólicas que funcionem como procedimentos de suplências, possibilitando a localização de um ponto de ancoragem para o gozo. Novas formas de enlace, sem o apoio do Nome-do-Pai, podem funcionar como ponto de capitonê, sustentando, desse modo, a estabilização e a construção de laços com o Outro.

Nesse sentido, é preciso que o analista esteja atento às soluções dadas pelo próprio sujeito, as quais muitas vezes passam despercebidas pelos demais técnicos da equipe. Isso exige uma imensa disponibilidade para dar lugar ao inesperado, ao que não estava inscrito. Nessa perspectiva, elegemos como condição príncipe da prática analítica na instituição um analista cúmplice com a imprevisibilidade do real, deixando-se guiar pela via da contingência. Assim, é preciso estar atento ao inusitado, ao que não é possível de ser coletivizado pela equipe ou assimilado pelo sujeito. Se o analista é um a mais no contexto institucional, é, por outro lado, aquele que suporta o intratável, o resto não eliminável da hiância que constitui a divisão inaugural do sujeito. $\mathrm{O}$ caso (do latim cadere, cair para baixo) é o instrumento de ação da prática analítica na instituição; nessa prática, o analista, inclinando-se ao leito, resgata o sujeito falante. A clínica, como diz Miller (Miller, 1996: 159), inspirando-se em Nabokov (nas Conferências sobre literatura), é uma questão de "divinos detalhes". 


\section{REFERÊNCIAS BIBLIOGRÁFICAS}

Alvarenga, E. (1999). A clínica das psicoses: o trabalho criativo e seus efeitos na clínica da psicose. Curinga: Revista da Escola Brasileira de Psicanálise, 13, 118-121. Belo Horizonte. - (2000). Psicoses freudianas e lacanianas. Opção lacaniana: Revista Brasileira Internacional de Psicanálise, 28, jul. 2000, 40-43. São Paulo.

Barreto, F. P. (2204). A urgência subjetiva na saúde mental. Opção lacaniana: Revista Brasileira Internacional de Psicanálise, 40, ago. 2004, 47-51. São Paulo.

Benetti, A. (1996). Interpretação na psicose ou manobras na transferência? Opção Lacaniana: Revista Brasileira Internacional de Psicanálise, 15, abr. 1996, 89-95. São Paulo.

Ferreira, C. M. R.; Trópia, M. R. A. B. (2000). Estabilização: o escriturário das suplências. Curinga: Revista da Escola Brasileira de Psicanálise, 14, abr. 2000, 144-150. Belo Horizonte.

Figueiredo. A. C. (1997). Vastas confusöes e atendimentos imperfeitos: a clínica psicanalitica no ambulatório público, $3^{\mathrm{a}}$ ed. Rio de Janeiro: Relume-Dumará.

Freud, S. (1905 [1904]). Sobre a psicoterapia. Obras psicológicas completas de Sigmund Freud. Direção de Tradução Jayme Salomão, 2a ed., Standard Brasileira. Rio de Janeiro: Imago, 1969.

. (1911). Notas psicanalíticas sobre um relato autobiográfico de um caso de paranóia (dementia paranoides). Obras psicológicas completas de Sigmund Freud. Direção de Tradução Jayme Salomão, 2a ed., Standard Brasileira. Rio de Janeiro: Imago, 1969.

Goldberg, J. (1996). Três projetos institucionais e suas possibilidades de atuação. Em Goldberg, J. A clínica da psicose: um projeto na rede pública, 2a ed. Rio de Janeiro: Te Corá Editora.

Julien, P. (1999). As psicoses: um estudo sobre a paranóia comum. Rio de Janeiro: Companhia de Freud.

Lacan, J. (1998a). Variantes do tratamento-padrão. Em Escritos (pp. 325-364). Tradução Vera Ribeiro. Rio de Janeiro: Jorge Zahar.

- (1998b). De uma questão preliminar a todo tratamento possível da psicose. Em Escritos (pp. 537-590). Tradução Vera Ribeiro. Rio de Janeiro: Jorge Zahar.

- (1998c). A direção do tratamento e os princípios de seu poder. Em Escritos (pp. 591-652). Tradução Vera Ribeiro. Rio de Janeiro: Jorge Zahar.

. (1998d). Do "Trieb" de Freud e do desejo do psicanalista. Em Escritos (pp. 865-868). Tradução Vera Ribeiro. Rio de Janeiro: Jorge Zahar.

. (2003a). Apresentação das memórias de um doente dos nervos. Em Outros escritos (pp. 219-223). Tradução Vera Ribeiro. Rio de Janeiro: Jorge Zahar.

. (2003b). Joyce, o sintoma. Em Outros escritos (pp. 560-566). Tradução Vera

Ribeiro. Rio de Janeiro: Jorge Zahar. 
(1955-1956). O seminário. Livro 3. As psicoses. Tradução Aluisio Menezes. 2a ed. Rio de Janeiro: Jorge Zahar, 1988.

. (1975-1976). O seminário. Livro 23. O sinthoma. Tradução Mário Almeida. Recife: Publicação para uso interno do Centro de Estudos Freudianos do Recife, inédito. - (2001). Abertura da seção clínica. Opção lacaniana: Revista Brasileira Internacional de Psicanálise, 30, abr. 2001, 06-09. São Paulo.

. (2000). Uma psicose lacaniana: entrevista conduzida por Jacques Lacan. Opção lacaniana: Revista Brasileira Internacional de Psicanálise, 26/27, abr. 2000, 05-16. São Paulo.

Laurent, E. (1999). A cidade analítica: o analista cidadão. Curinga, 13, 12-19. Belo Horizonte: Escola Brasileira de Psicanálise.

. (2000). Psicanálise e saúde mental: a prática feita por muitos. Curinga, 14, 164-175. Belo Horizonte: Escola Brasileira de Psicanálise.

Mattos, S. (2003). A disponibilidade do analista. Correio: Revista da Escola Brasileira de Psicanálise, 42, abr. 2003, 19-26. Belo Horizonte.

Miller, J.-A. (1996). Produzir o sujeito?. Em Matemas I (pp. 155-161). Tradução Sérgio Laia. Rio de Janeiro: Jorge Zahar.

Miller, J.-A et al. (1998). Os casos raros, inclassificáveis da clínica psicanalítica: a conversação de Arcachon. São Paulo: Biblioteca Freudiana Brasileira.

. (1999). Psicose ordinária e clínica imprecisa. Em Jornada da Escola Brasileira de Psicanálise, 6, 12-15. Salvador: Escola Brasileira de Psicanálise, dez. 1999.

. (2002). O real é sem lei. Opção lacaniana: Revista Brasileira Internacional de Psicanálise, 34, out. 2002, 07-16. São Paulo.

. (2003). O último ensino de Lacan. Opção lacaniana: Revista Brasileira Internacional de Psicanálise, 35, jan. 2003, 06-24. São Paulo.

Quinet, A. (1997). Teoria e clínica da psicose. Rio de Janeiro: Forense Universitária.

Silvestre, M. (1991a). Transferência e interpretação nas psicoses. Em Amanhã, a psicanálise (pp. 127-135). Tradução Ari Roitman. Rio de Janeiro: Jorge Zahar.

. (1991b). Um psicótico em análise. Em Amanhã, a psicanálise (pp. 136-141). Tradução Ari Roitman. Rio de Janeiro: Jorge Zahar.

Stevens, A. (1998) A renovação da clínica por Lacan. Curinga: Revista da Escola Brasileira de Psicanálise, 12, set. 1998, 104-112. Belo Horizonte.

. (1999). A clínica psicanalítica nas instituições: psicanálise e saúde mental. Curinga: Revista da Escola Brasileira de Psicanálise, 13, 42-49. Belo Horizonte.

Tenório, F. (2001a). A psicanálise e a clínica da reforma psiquiátrica. Rio de Janeiro: Rios Ambiciosos.

. (2001b). Reforma psiquiátrica e psicanálise: um trabalho necessário. Em

Figueiredo, A. C.; Cavalcanti, M. T. (Orgs.). A reforma psiquiátrica e os desafios da 
desinstitucionalização: contribuições à III a Conferência Nacional de Saúde Mental (pp. 85 a 99). Rio de Janeiro: IPUB/CUCA.

Viganò, C. (1999). A clínica psicanalítica nas instituições: a construção do caso clínico em saúde mental. Curinga: Revista da Escola Brasileira de Psicanálise, 13, 50-59. Belo Horizonte.

. (2003). Casos clínicos e figuras do outro institucional: a construção do caso. Em Almanaque de psicanálise e saúde mental, 1, nov. 1998, 47-50. Belo Horizonte: Instituto de Psicanálise e Saúde Mental de Minas Gerais.

Zenoni, A. (1999). Pertinência da clínica diferencial. Opção lacaniana: Revista Brasileira Internacional de Psicanálise, 25, out., 30-32. São Paulo.

. (2000). A psicose fora do desencadeamento. Opção lacaniana: Revista Brasileira Internacional de Psicanálise, 28, jul. 2000, 36-39. São Paulo.

\section{Notas}

1 Expressão usada por Sérgio de Mattos, em seu texto "A disponibilidade do analista" (2003), para indicar que o psicanalista na instituição deve se prestar a usos distintos daqueles baseados em padrões pré-determinados.

2 Denominação baseada no que Jacques-Alan Miller chamou la pratique à plusieurs, com o propósito de caracterizar a práxis psicanalítica desenvolvida em algumas instituiçôes européias.

3 Ensinamento pronunciado nos quadros do Departamento de Psicanálise de Paris VIII.

Recebido em 11 de fevereiro de 2006 Aceito para publicação em 22 de abril de 2006 